\title{
Asymmetric capacitors using lignin-based hierarchical porous carbons
}

David Salinas-Torres ${ }^{\mathrm{a}}$, Ramiro Ruiz-Rosas ${ }^{\mathrm{a}}$, María José Valero-Romero ${ }^{\mathrm{b}}$, José RodríguezMirasol $^{\mathrm{b}}$, Tomás Cordero ${ }^{\mathrm{b}}$, Emilia Morallón $^{\mathrm{c}}$, Diego Cazorla-Amorós ${ }^{\mathrm{a},{ }^{*}}$

${ }^{a}$ Instituto Universitario de Materiales, Departamento de Química Inorgánica, University of Alicante, Alicante, Spain

${ }^{\text {b }}$ Departamento de Ingeniería Química, University of Málaga, Málaga, Spain

'Instituto Universitario de Materiales, Departamento de Química Física, University of Alicante, Alicante, Spain

*Corresponding author: cazorla@ua.es. Diego Cazorla-Amóros, Departamento de Química Inorgánica e Instituto Universitario de Materiales, University of Alicante, P.O. Box 99, San Vicente del Raspeig, E-03080, Alicante, Spain. Phone number: +34965903946. 


\begin{abstract}
Hierarchical porous carbons (HPC) were fabricated from lignin by hard template method using Beta and $\mathrm{Y}$ zeolites as templates. Textural properties were dictated by the hard template, obtaining a bi-modal pore size distribution with similar micropore sizes but different mesopore sizes. These HPCs provide a well-connected and developed porosity that show capacitance values near to $140 \mathrm{~F} \mathrm{~g}^{-1}$ in $1 \mathrm{M} \mathrm{H}_{2} \mathrm{SO}_{4}$ at $1 \mathrm{~A} \mathrm{~g}^{-1}$ and a capacitance retention of ca. $50 \%$ and $40 \%$ when the specific current is increased from 1 to $64 \mathrm{~A} \mathrm{~g}^{-1}$ for the $\mathrm{Y}$ and the Beta-based carbons, respectively. A symmetric capacitor working at $1.2 \mathrm{~V}$ with energy densities of $4.8 \mathrm{Wh} \mathrm{kg}^{-1}$ at 0.5 $\mathrm{kW} \mathrm{kg}^{-1}$ has been obtained using the Beta-based HPC. Asymmetric in mass design allowed to operate the capacitor safely at $1.4 \mathrm{~V}$, yielding an energy density of $7.3 \mathrm{Wh} \mathrm{kg}^{-1}$ at $0.5 \mathrm{~kW} \mathrm{~kg}^{-1}$, a increase of $50 \%$ with respect to the symmetric configuration, while keeping a maximum power of $46 \mathrm{~kW} \mathrm{~kg}^{-1}$. This capacitor has an energy density comparable to that of a symmetric supercapacitor built using a commercial activated carbon of much higher porosity development, outperforming it in terms of energy, coulombic efficiencies and maximum power.
\end{abstract}

Keywords: Supercapacitors, Hierarchical Porous Carbon, Lignin, Green Chemistry

\title{
Graphical abstract
}




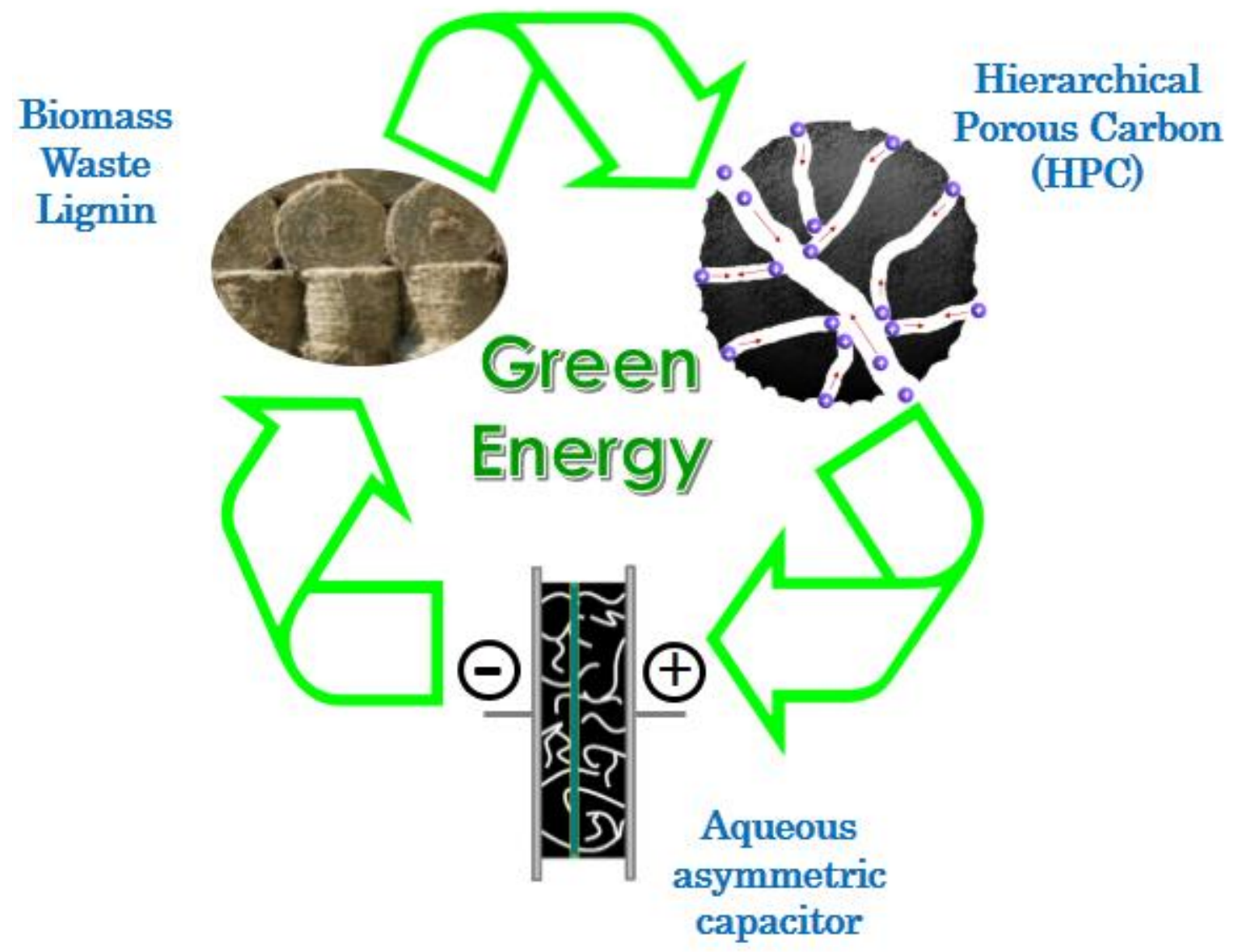




\section{Highlights}

- Green supercapacitors constructed with lignin-based HPC in aqueous electrolyte

- Asymmetric design allowed to safely expand the voltage to $1.4 \mathrm{~V}$

- Performance comparable to commercial activated carbon in spite of its lower porosity

- Higher power densities can be achieved with the HPC compared to commercial AC 


\section{Introduction}

The ever increasing energy demand along with the environmental concerns of our society have generated a need for new and more sustainable techniques, devices and materials for the production and storage of energy. In the field of supercapacitors, carbon materials have taken the role as electrode materials due to the combination of excellent performance (high electrical conductivity, high surface area and pore volume) and electrochemical stability with a reduced production cost.

Supercapacitors are of high interest since their features complement other energy production and storage devices, such as batteries and fuel cells. Their most relevant parameter is the power density, which allows them to serve in power-demanding applications where other devices cannot be employed, such as consumer electronics, electric vehicles and power management [1]. The high power density of supercapacitor arises from their energy storage mechanism, which is based in the electrostatic interaction between the polarized surface of the porous carbon electrode and the ions of the electrical double layer formed in the electrode-liquid interface [2]. When increasing the sustainability and safety and reducing the toxicity of supercapacitors by using greener materials for electrodes (as sustainable carbon materials) and electrolytes (i.e. aqueousbased electrolytes), it is mandatory to preserve the power characteristics of these devices, while increasing as much as possible the energy density of the novel systems.

For keeping a high power density, it is necessary to combine a carbon material of high electrical conductivity and good ion transport through the pore network with an electrolyte of high ionic conductivity. Aqueous-based electrolytes are the best suited in this sense, although their small stability potential window have traditionally hampered their use, since it reduces the energy density of the cell. Recently, it has been shown that the stability of the potential window of aqueous electrolytes can be expanded by modifying the surface chemistry of the porous carbon electrodes [3-8]. Another strategy for increasing the voltage of aqueous-based electrolytes is the use of asymmetric configuration in mass electrodes [9], being optimized from the balance of charge by using the maximum allowable potential window of each electrode [10]. Its implementation has allowed to reach cell voltages as high as $1.9 \mathrm{~V}$ in aqueous-based electrolyte 
[11], being highly helpful for the development of more sustainable supercapacitor devices based on greener electrolytes and carbon materials.

On the material side, the power characteristic of the materials is also connected to the electrical conductivity and the ion mobility in the pore network $[1,12,13]$. The use of zeolite templated carbons, which are hard templated carbon materials obtained as the negative replica of a parent zeolite infiltrated with a carbon precursor [14,15], has proven that an ordered arrangement of highly interconnected pores leads to enhanced capacitance retention under high power demanding conditions [16]. A direct comparison between the electrochemical performance of the highly microporous Maxsorb and activated ordered mesoporous carbon demonstrated that the presence of mesopores in the pore size distribution also contributes to promote the capacitance retention of the electrodes, since it facilitates the use of the surface of the micropores [17]. As for the arrangement of porosity, hierarchical porous carbons, where pores with different sizes are spatially ordered in the structure of the carbon material, have demonstrated that the presence of mesopore reservoirs connected to the micropores allow fast and smooth ion diffusion between micropores and mesopores, delivering an improved capacitance retention compared to other carbon materials with meso and micropores that are disordered [18].

Finally, the production of carbon materials from green, renewable and sustainable sources is of high interest [19]. In this sense, the use of lignocellulosic raw materials or processed fractions for the synthesis of porous carbon materials is straightforward, and lignin is one of the better placed materials for fulfilling that purpose [20]. Thanks to its low cost, high carbon content and high aromaticity, the use of lignin as raw material for the preparation of advanced carbon materials has been in the focus of the scientific community for a long time, and since the rise of the woodto-ethanol bio-refineries, where lignin is also obtained as a by-product in large amounts, the development of novel value-added products from lignin has been invigorated [21]. It has been profited in the past for the production of activated carbons [22,23], high temperature carbons [24], carbon fibers [25,26], electrospun carbon fibers [27,28] and porous carbon electrodes [29]. In the supercapacitor field, lignin-based porous carbons [30-34] and electrospun fibers [35-37] have already been utilized as sustainable carbon electrodes. 
We have recently reported that hierarchical porous carbons (HPCs) can be obtained through a hard template method upon carbonization of organosolv lignin-zeolite mixtures [38,39]. To our knowledge, there are only two studies in the literature dealing with the production of HPCs from lignin for supercapacitor applications, and both of them relies on the use of $\mathrm{KOH}$ as activating agent in order to promote porosity [33,34]. Contrarily, our lignin-based HPCs were produced by direct carbonization of the lignin-zeolite mixtures, without requiring any other activating agent than the hard template. Moreover, these materials showed interesting electrochemical behavior in $1 \mathrm{M} \mathrm{H}_{2} \mathrm{SO}_{4}$, obtaining in some cases capacitances over $250 \mathrm{~F} \mathrm{~g}^{-1}$ at $50 \mathrm{~mA} \mathrm{~g}^{-1}$. Thanks to the presence of mesopores connected to the micropore network, these capacitance values were well retained when the current density was increased up to $20 \mathrm{~A} \mathrm{~g}^{-1}$ (capacitance retention higher than $50 \%$ without discounting the ohmic drop). In this work, we propose to combine the use of ligninbased HPCs with the asymmetric in mass design in order to build more sustainable supercapacitor cells in an aqueous-based electrolyte with superior performance. The performance and durability of the obtained supercapacitors is reported. Further comparison with a symmetric supercapacitor assembled with a commercial activated carbon used for capacitors preparation has been also detailed.

\section{Experimental}

\subsection{Materials and preparation of lignin-based HPCs}

Alcell Lignin, provided by Repar Technologies Inc., has been used as the carbon precursor. The Alcell process is one of the most utilized of the organosolv category, and allows the recovery of a high purity lignin, which only contains a small amount of inorganic compounds, through the use of a more environmental friendly pulping process[20]. Zeolite Y (CBV 300) and Zeolite $\beta$ (CP $814 \mathrm{E}$ ) in ammonium form have been acquired from Zeolyst International Company (PA, USA) and used as received as the hard templates. The preparation process of the HPCs has been carried out following the protocol derived by Valero-Romero et al. [38]. Briefly, it implies three steps. First, lignin has been solved in ethanol, and the zeolite has been added to the solution using a 1:1 lignin to zeolite weight ratio. The mixture has been stirred for $1 \mathrm{~h}$ and dried at $60{ }^{\circ} \mathrm{C}$ for one day. Secondly, carbonization of the mixture was carried out at $900{ }^{\circ} \mathrm{C}$ for $2 \mathrm{~h}$ under

continuous $\mathrm{N}_{2}$ flow $\left(150 \mathrm{~cm}^{3} \mathrm{STP} / \mathrm{min}\right)$. Finally, the zeolite template has been removed by refluxing the carbonized mixture in sodium hydroxide $1 \mathrm{M}$ for $6-24 \mathrm{~h}$, washed with distilled water 
and dried at $120^{\circ} \mathrm{C}$ overnight. Samples were manually milled and sieved under 50 microns size. The obtained HPCs have been named L-Y-900 (HPC obtained using Y-zeolite as hard template) and L-B-900 (HPC obtained using $\beta$ zeolite as hard template). The preparation yields are $45 \%$ and $35 \%$ for $\mathrm{Y}$ and $\beta$-based hierarchical porous carbons, respectively. Ash content lower than $0.5 \%$ has been found in these materials. The main elements found by XPS over the surface of these materials were carbon and oxygen with mass surface concentrations of around 84-86\% and $12-15 \%$, respectively, followed by small amounts of nitrogen, $1-2 \%$. Aluminum and silicon were detected in quantities lower than $0.5 \%$.

A commercial activated carbon was used in the construction of supercapacitor cells for comparison purposes (sample ACJM).

\subsection{Physicochemical and electrochemical characterization of the electrodes.}

The textural properties of the HPCs have been evaluated by nitrogen adsorption-desorption isotherms at $-196{ }^{\circ} \mathrm{C}$ using an automatic adsorption system (Autosorb-6b, Quantrachrome) after out-gassing the samples under vacuum at $200^{\circ} \mathrm{C}$ for $4 \mathrm{~h}$. Specific surface areas $\left(\mathrm{S}_{\mathrm{BET}}, \mathrm{m}^{2} \mathrm{~g}^{-1}\right)$ have been determined by BET method in the relative pressure range of 0.05-0.16. Micropore volumes (pore sizes below $2 \mathrm{~nm}, \mathrm{~V}_{\mathrm{DR}}, \mathrm{cm}^{3} \mathrm{~g}^{-1}$ ) have been assessed by applying the DubininRadushkevich theory to the $\mathrm{N}_{2}$ adsorption isotherm in range of relative pressures $0.005<\mathrm{P} / \mathrm{P}_{0}<$ 0.05. Mesopore volumes $\left(\mathrm{V}_{\text {meso }}, \mathrm{cm}^{3} \mathrm{~g}^{-1}\right)$ have been determined by difference between the amount of adsorbed nitrogen at relative pressures of 0.20 and 0.95 . The pore size distribution for both samples has been calculated from the $\mathrm{N}_{2}$ adsorption isotherms using the 2D-NLDFT Heterogeneous surface model [40] and by applying the Solution of Adsorption Integral Equation Using Splines (SAIEUS, available online at http://www.nldft.com/) Software.

The surface chemistry of the samples has been analyzed by Temperature-ProgrammedDesorption (TPD) experiments, which have been performed heating a small amount ( 10 $\mathrm{mg})$ of sample in a TGA-DSC instrument (TA Instruments, SDT Q600) at $20^{\circ} \mathrm{C} \mathrm{min}^{-1}$ up to $900{ }^{\circ} \mathrm{C}$

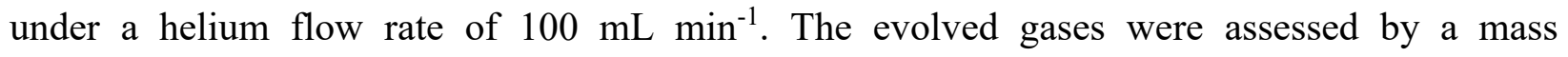
spectrometer (Thermostar, Balzers, BSC 200) that is coupled to the gas outlet of the TG instrument. The calibration of the equipment for $\mathrm{H}_{2} \mathrm{O}, \mathrm{CO}$ and $\mathrm{CO}_{2}$ evolutions has been done using the decomposition of a calcium oxalate (99.999\%, Sigma-Aldrich) standard. 
Carbon electrodes have been prepared by physical mixing for 30 minutes of the HPCs with acetylene black and polytetrafluoroethylene (PTFE) in a weight ratio of 90:5:5. For shaping the electrodes, a sample sheet of 6-8 mg (active material) has been cut into a circular shape with a surface area of $0.67 \mathrm{~cm}^{2}$ and pressed for $5 \mathrm{~min}$ at 2 tons to guarantee a homogeneous thickness. After that, the electrodes have been tightly pressed onto a gold disk used as current collector for the electrochemical characterization in a three electrode cell. The electrodes have been submerged for 2 days into $1 \mathrm{M} \mathrm{H}_{2} \mathrm{SO}_{4}$ previously to electrochemical measurements. The electrochemical behavior of the HPCs electrodes in $1 \mathrm{M} \mathrm{H}_{2} \mathrm{SO}_{4}$ has been assessed in a three electrode T-type Swagelock cell. A nylon membrane has been used as separator between the electrodes. A commercial activated carbon has been used as counter electrode. $\mathrm{An} \mathrm{Ag} / \mathrm{AgCl} / \mathrm{Cl}^{-}$ (sat.) electrode has been used as reference electrode. Cyclic Voltammetry (CV) at $5 \mathrm{mV} \mathrm{s}^{-1}$ has been employed for assessing the electrochemical stability of the electrodes, while Galvanostatic Charge-Discharge (GCD) experiments at different specific currents have allowed to determine the capacitance of the HPC carbon electrodes.

\subsection{Construction of supercapacitor cells}

The electrochemical performance of symmetric and asymmetric HPC capacitors has been analyzed by using Swagelock two-electrode cells with stainless steel as current collectors (surface area of $0.196 \mathrm{~cm}^{2}$ ) in $1 \mathrm{M} \mathrm{H}_{2} \mathrm{SO}_{4}$ solution. The carbon electrodes have been prepared following the protocol described in section 2.2, and have been attached to the current collectors using a conducting adhesive (colloidal graphite suspension, Hitasol GA-715, Hitachi Chemical Co., Ltd.). The commercial activated carbon (ACJM) has been also employed as carbon electrode for the construction of symmetric capacitors for comparison purposes. All these capacitors have been tested using an Arbin SCTS instrument by galvanostatic charge-discharge cycles at different specific currents between 0.5 and $64 \mathrm{~A} \mathrm{~g}^{-1}$. A Swagelock three-electrode cell equipped with an $\mathrm{Ag} / \mathrm{AgCl} / \mathrm{Cl}^{-}$(sat.) reference electrode has been used for tracking separately the potential of the each electrode during these experiments (positive and negative one). The specific capacitance of the 2-electrode cells was estimated from the discharge cycle in the chronopotentiometric experiments and was referred to the total weight of the active material of both electrodes. The energy density was determined from the area below the $\mathrm{U}$ vs $\mathrm{Q}$ discharge curve, while the power density results from dividing the energy density by the discharge time. 
Coulombic efficiencies are determined as the ratio between the discharge and charge times, while energy efficiencies are evaluated as the ratio between the discharge and charge energies. The cell resistances have been evaluated using electrochemical impedance spectroscopy (EIS) in an Autolab PGSTAT302. Impedance spectra were measured at $0.05 \mathrm{~V}$ in the frequency range of $10 \mathrm{mHz}$ to $100 \mathrm{kHz}$ with an amplitude for the voltage signal of $10 \mathrm{mV}$ (root-mean-square).

\section{Results and Discussion}

\subsection{Characterization of HPCs}

HPCs have been prepared from lignin following the protocol detailed elsewhere [38]. After mixing lignin and zeolites and the carbonization of the resulting mixture, zeolite was removed using a washing step in NaOH. Particles of L-Y-900 inherited the size and morphology of $\mathrm{Y}$ zeolite crystals. In the case of Beta zeolite, particles are composed of nanocrystals of about 17 $\mathrm{nm}$ which are aggregated in a manner that retains intercrystalline mesopores of around 10-50 nm diameters. Thus, lignin may not only infiltrate the zeolite micropores, but also deposit or cover the zeolite external surface (i.e., the mesopore wall surface), resulting in hierarchical porous carbons after carbonization and removal of the zeolite template. TEM images in ref. [38] show that HPCs present two well-differentiated structures: a dense and compact structure forming the external boundary of the carbon particles mainly composed of pyrolytic carbon and a less dense and less ordered structure constituting the inner part of the carbon particle. Mesopores of sizes between 10 and $50 \mathrm{~nm}$ can be found in the case of L-B-900, while mesopores of much smaller size, 3 to $5 \mathrm{~nm}$, are seen in the bulk of the carbon particles for L-Y-900. In both cases, micropores are located in the disordered structure that is seen around mesoporosity, rendering a highly interconnected and hierarchically arranged porosity.

Fig. 1A shows the nitrogen adsorption-desorption isotherms of the L-Y-900 and L-B-900 HPCs in powder form, and Fig. 1B compiles the derived NLDFT pore size distribution (PSD) of both samples. It can be clearly seen that the structure of the hard template has a strong influence on the porosity of the resulting HPC. Those obtained using Y-zeolite have a nitrogen isotherm with a high gas uptake at low relative pressure, small slope in the intermediate region and a small hysteresis loop that closes at a relative pressure of 0.4 , pointing out the predominance of micropores with a small contribution of mesoporosity in this sample. On the other hand, the L-B900 showed a steeper nitrogen adsorption isotherm than L-Y-900 and a large hysteresis loop at 
relative pressures of $0.7-0.9$, indicative of a material with a large contribution of both micropores and mesopores. The shape of the nitrogen adsorption isotherm for the commercial activated carbon ACJM shows that it is mainly microporous. The pore size distributions confirm these comments, and have revealed that, while both HPCs have a similar amount of micropores and of similar sizes (see inset of Fig. 1B), the mesoporosity is very different. L-Y-900 contains narrow mesoporosity that mostly falls in the $2-6 \mathrm{~nm}$ region, whereas the mesoporosity of L-B-900 is much wider in size and in volume, with a well-defined size distribution that ranges between 7 and $24 \mathrm{~nm}$, showing a clear maximum at $13 \mathrm{~nm}$. It also presents a small contribution of narrow mesoporosity in the surroundings of $4 \mathrm{~nm}$. ACJM has most of the pore size distribution centered in the microporosity region, keeping $95 \%$ of its pore volume restricted to pore sizes below $2 \mathrm{~nm}$. Table 1 compiles the textural properties derived from the nitrogen adsorption isotherms. Both the micropore and mesopore volumes of L-B-900 surpass those of L-Y-900, while the differences between the specific surface areas are smaller, with L-B-900 showing the highest specific surface area. These results are in agreement with the results obtained in previous works for the preparation of lignin-based HPCs [38,39], where a detailed discussion regarding the differences in the origin of the mesopores of these samples is provided. As discussed before, ACJM doubles both the surface area and pore volume of L-B-900, but lacks of any relevant contribution of mesopores when compared with the HPCs materials.

In a previous work, it was found that the lignin-based HPCs showed a rich surface chemistry with a high oxygen and nitrogen concentration that originates from both the dehydroxilation and the transference of nitrogen from the ammonium cations of the zeolites to the HPC [39]. In the case of the materials prepared in this work, the main elements found by XPS over the surface of these materials were carbon and oxygen with weight surface concentrations of around $82 \%$ and $15 \%$, respectively. Nitrogen was also detected, mainly, in that material derived from Y zeolite ( $2 \%$ vs $1 \%$ in the case of $\beta$ zeolite), which we have related to the higher ammonium content of this zeolite. Other elements such as aluminum and silicon were detected at very low concentrations (less than 1\%), which indicates the success of the demineralization and washing step. Some of these surface groups are of great interest, since they deliver pseudocapacitance and wettability to the surface of carbon materials [41,42], rendering interesting features from the electrochemical point of view. Therefore, the surface oxygen groups over the surface of the HPCs and the commercial ACJM carbon have been studied by $\mathrm{CO}$ and $\mathrm{CO}_{2}$ TPD experiments 
(Fig. S1). These profiles are related to the decomposition of surface oxygen groups, and reveal both their nature and their amount $[43,44]$. The total amount of evolved $\mathrm{CO}$ and $\mathrm{CO}_{2}$ gases and the equivalent oxygen amount (estimated as $\mathrm{CO}+2 \cdot \mathrm{CO}_{2}$ ) are enlisted in Table $\mathbf{1}$. It can be seen that the use of Y-zeolite produced a larger amount of oxygen functionalities. This difference arises from the higher amount of hydroxyls, quinones and carboxylic acids formed in L-Y-900, which seems to be connected to the structure of the hard template. The large reactivity towards oxygen (and hence the tendency to form surface oxygen groups) of zeolite templated carbons prepared using Y-zeolite has already been reported in the literature [45]. The CO profile for LY-900 exhibits a high CO evolution at high temperatures, which indicates the presence of highly stable CO-type groups. The commercial activated carbon has a similar oxygen content than L-Y900 but with a different distribution of functionalities, especially for the CO-type. It also has a higher oxygen content than L-B-900. However, when the concentration of surface oxygen groups is expressed in terms of surface area, the commercial activated carbon and L-B-900 have a similar amount of oxygen in their surface, around $1 \mu \mathrm{mol} \mathrm{O} \mathrm{m}^{-2}$, which points out that both materials have a similar degree of oxidation, while it is much higher for L-Y-900 $\left(3.4 \mu \mathrm{mol} \mathrm{O} \mathrm{\textrm {m } ^ { - }}\right.$ ).

\subsection{Electrochemical characterization of HPCs}

\subsubsection{Cyclic voltammetry.}

As aforementioned, both HPC were characterized in a three-electrode cell by cyclic voltammetry. Firstly, a study of the stability potential window was performed in order to determine the upper and lower potential limits, which play a key role in the design of the asymmetric capacitor. It is noteworthy to mention that L-Y-900 is easily electrooxidized when it is polarized at positive potentials due to the presence of highly reactive edges sites on its structure [39], and therefore all L-Y-900 electrodes have been submitted to an electrochemical oxidation treatment consisting in 4 scans at $5 \mathrm{mV} \mathrm{s}^{-1}$ from EOCP to $1.0 \mathrm{~V}$ in order to stabilize their response before being characterized or mounted as electrode of a supercapacitor cell.

Regarding L-Y-900 sample, Fig. 2A presents a collection of steady voltammograms in acid medium from the $\mathrm{E}_{\mathrm{OCP}}(0.27 \mathrm{vs} \mathrm{Ag} / \mathrm{AgCl})$ where the potential limits have been step-wise opened towards more positive or less positive potential values. On the one hand, the voltammograms recorded from the EOCP down to $-0.2 \mathrm{~V}$ show a quasi-rectangular shape with some 
pseudocapacitance contribution in the region close to the E these samples in this potential range (between 0.27 and $-0.2 \mathrm{~V}$ ) arises from redox processes associated to the presence of CO-evolving oxygen groups [41]. It was also found that small irreversible currents were registered when the potential window was opened down to $-0.4 \mathrm{~V}$, being probably related to the irreversible electrochemical reduction of carbon materials [46] or to the hydrogen evolution reaction. The gravimetric capacitance determined from the negative and positive scan also starts to be unbalanced when the potential reaches values lower than $-0.4 \mathrm{~V}$ (i.e., coulombic efficiency is $99 \%$ at $-0.3 \mathrm{~V}, 98 \%$ at $-0.4 \mathrm{~V}$ and $91 \%$ at $-0.5 \mathrm{~V}$ ). For this reason, the lower potential limit of stability of L-Y-900 is determined as $-0.4 \mathrm{~V}$. On the other hand, the effect of the upper potential limit shows a rather different behavior. Instead of displaying the rectangular shape characteristic of pure capacitive electric storage, a broad peak attributable to reversible redox process appears close to $0.4 \mathrm{~V}$. They are also related to the presence of a high concentration of surface oxygen groups that evolve as CO during TPD (Table 1). These groups have been regarded as electroactive (like in the case of quinone/hydroquinone redox pair) and can be reversibly oxidized and reduced, thus storing energy through pseudocapacitance [41]. The voltammogram shapes recorded for L-Y-900 resembles those reported for other porous carbons prepared using the same zeolite as template $[47,48]$. The oxidation current registered near $1.1 \mathrm{~V}$ can be related to water oxidation and the electrochemical oxidation of the carbon material. Then, the upper potential limit of stability for this carbon material is determined as $1.0 \mathrm{~V}$.

Concerning the L-B-900 sample, the same procedure was used to study the stability in order to properly design an asymmetric capacitor. Fig. 2B shows the steady voltammograms for L-B-900 sample when opening the potential windows on the more positive potentials and the less positive potentials from the open circuit potential $\left(\mathrm{E}_{\mathrm{OCP}}=0.31 \mathrm{~V}\right)$. It can be seen that the electrochemical behavior is different to that of L-Y-900 sample. The contribution of the pseudocapacitance is much lower in this material, which can be related to the lower amount of CO-type surface oxygen groups, as discussed in section 3.1. The shape of the voltammograms is more rectangular in all the studied potential ranges for this carbon material. As for the potential limits for the design of the asymmetric capacitor, they were set to $-0.5 \mathrm{~V}$ for the lower potential limit and 1.0 $\mathrm{V}$ for the upper potential limit, since the coulombic efficiencies in these limits are over $95 \%$ for both of them. 
Specific capacitance for each carbon material has been determined at different potential ranges and compiled in Fig. 2C and D. It can be seen that capacitance obtained from the voltammograms diminishes with the upper potential limit for L-Y-900 electrode although for LB-900 it increases for the highest potential used due to the higher oxidation current observed for this material. This decrease in capacitance for L-Y-900 with the upper potential limit, which is due to the large amount of surface oxygen groups, is expected to be negative for the supercapacitor performance and stability [49,50]. Moreover, it can be seen that the capacitance, and therefore the stored charge, for the more positive potential range is higher for the L-B-900 material, indicating that this sample could be more suitable than L-Y-900 to maximize the storage in the capacitor.

For the asymmetric design, since capacitance values are clearly dependent on the potential for these materials, the gravimetric capacitance of the electrode will rely on the working potential range, and this fact must be adequately addressed during the characterization and when estimating the optimum mass ratio of the electrodes. In view of the above electrochemical characterization, a suitable upper potential limit to design the asymmetric capacitor based on HPC samples would be $1.0 \mathrm{~V}$.

\subsubsection{Capacitance determination and rate performance}

One of the most important issues to consider in the design of a reliable capacitor is the accurate determination of the gravimetric capacitance for positive and negative electrodes. These capacitances should be determined in the potential windows ranging from the EocP to the upper potential limit for the positive electrode, while for the negative one it should be calculated between $\mathrm{E}_{\mathrm{OCP}}$ and the lower potential limit. In this study, galvanostatic charge-discharge experiments have been used. Fig. 3A shows GCD curves for both samples ranging from Eocp up to $1.0 \mathrm{~V}$. A quasi-triangular shape can be observed for L-B-900 sample, which indicates that charge-discharge processes are mainly attributed to capacitive process, while L-Y-900 shape shows a strong deviation due to pseudocapacitive processes related to surface oxygen groups (Table 1). Furthermore, the ohmic drop for both samples is relatively low at $2 \mathrm{~A} \mathrm{~g} \mathrm{~g}^{-1}$. Therefore, it can be said that these HPCs have a suitable connectivity between pores, since the ion diffusion seems not to be hindered and the electric double layer formation is facilitated. Regarding the 
potential window for the negative electrodes (Fig. 3B), GCD curves exhibit the same shape in the case of L-B-900 sample. However, L-Y-900 sample no longer shows a distorted triangular shape. At this point, it can be said that the capacitance contribution of surface oxygen groups is not important for the negative electrode.

Fig. 4 shows the evolution of the specific capacitance with the current density for both samples and for the two potential windows studied. It can be observed that all samples present good capacitance retention values at high current densities for both the positive and negative potential windows. These values are comparable to those found in the literature. L-B-900 sample shows a better performance than L-Y-900, which could be due to the more difficult ion diffusion inside the porosity for L-Y-900 than L-B-900, which is in agreement with the highest mesopore volume for sample L-B-900 (Table 1).

\subsection{Construction and characterization of lignin-based HPC capacitors}

\subsubsection{Symmetric capacitors}

The most conventional design implies that both electrodes of the capacitor are constructed using the same electrode thickness what means the same specific weight $\left(\mathrm{mg} \mathrm{cm}^{-2}\right)$. For the first comparison of the performance of HPCs and the commercial activated carbon ACJM, symmetric cells were constructed. Specific weights of 7.3 and $6.7 \mathrm{mg} \mathrm{cm}^{-2}$ for each electrode were employed in the formulation of the L-Y-900 and the L-B-900 capacitors. Since this parameter is directly related to the electrode thickness, which has a relevant impact in the performance of the capacitor [51], these values have been chosen in order to ensure that the thickness of the HPC electrodes are comparable between capacitors (160 and $180 \mu \mathrm{m}$ for the L-Y-900 and L-B-900, respectively) and also in the same range that is used in commercial cells. The ACJM capacitor has been constructed similarly: $7.0 \mathrm{mg} \mathrm{cm}^{-2}$ of specific weight of the electrode and thickness of $150 \mu \mathrm{m}$.

After the capacitor construction, all the cells were submitted to charge-discharge experiments at different constant current from 1 to $64 \mathrm{~A} \mathrm{~g}^{-1}$. Two hundred cycles were recorded at each specific current for ensuring a stable response of the capacitor. This characterization protocol was repeated while the cut-off voltage was sequentially opened from 0.8 up to $1.2 \mathrm{~V}$. Fig. 5 compiles, as an example, the GCD profiles (cycle 195 $5^{\text {th }}$ ) with specific current of $1 \mathrm{~A} \mathrm{~g}^{-1}$ for the three symmetric capacitors working at cut-off voltages from $0.8 \mathrm{~V}$ up to $1.2 \mathrm{~V}$. It can be seen that 
different behaviors are obtained for L-B-900 and L-Y-900 capacitors. L-B-900 capacitor produces triangular charge-discharge profiles which are characteristic of pure capacitive systems with voltage-independent capacitance, whereas the capacitance of L-Y-900 is strongly related to the voltage, due to the large contribution of redox reactions to the overall capacitance of the carbon material in the positive electrode. Moreover, the capacitance and electrochemical behavior of the L-B-900 capacitor remains stable when the cut-off potential is increased from 0.8 up to $1.2 \mathrm{~V}$, a feature that is not observed in the case of L-Y-900. ACJM capacitor has a similar behavior to L-B-900, although a small faradaic contribution is detected at $1.2 \mathrm{~V}$ (see the small deviation of the linearity on the upper end of the charge curve at $1.2 \mathrm{~V}$ ), a finding probably related to undesired reactions of either the electrode or the electrolyte. Capacitances at $1.2 \mathrm{~V}$ can be calculated from the discharge branch of the GCD experiments at $1 \mathrm{~A} \mathrm{~g}^{-1}$, being $56 \mathrm{~F} \mathrm{~g}^{-1}, 29 \mathrm{~F}$ $\mathrm{g}^{-1}$ and $22 \mathrm{~F} \mathrm{~g}^{-1}$ for the ACJM, the L-B-900 and the L-Y-900 capacitors, respectively. As expected, ACJM outperforms the HPCs due to its larger surface area (Table 1).

The cell resistances have been evaluated by EIS measurements. Fig. 5D presents the Nyquist plot of the three capacitors. A low and fairly similar values for the resistance associated to the construction of the cell (first intercept on the Z'axis) are observed in all cases (around 0.61-0.65 $\Omega$ at $100 \mathrm{kHz}$ ), reflecting the high conductivity of the whole cell, including that of the electrode materials, while some differences were found in the diameters of the semicircle between the HPCs and the commercial activated carbon (see inset in Fig. 5D), being higher in the latter case. In electric double layer capacitors, the size of the semicircle is related to the resistance of charge transfer through the grain-boundaries at the rough electrode-electrolyte interface [52] that allows dielectric polarization of the solution [53]. Then, it will be influenced by the continuity, connectivity and porosity of the electrode [54]. Since the three electrodes share the same formulation and preparation procedure, the lower diameter of the semicircle in the case of HPCs is indicative of a better electrical conductivity and charge propagation, that may be associated to the suitable properties of lignin as carbon material to produce ordered structures [36] and to the interconnected porosity. Higher differences are observed in the Equivalent Distributed Resistance (EDR), in the high-medium frequencies region, between the HPCs and ACJM capacitors. EDR is related to the electrolyte resistance within the pore system of carbon materials [53], where the ion diffusion time constants associated to different pore sizes, pore shapes and tortuosity in the pore network can be modelled as a series of electrical resistances that connects 
the capacitance associated to each pore [54]. This resistance is reflected in the Nyquist plot as the $45^{\circ}$ slope line that runs from the end of the semicircle to the beginning of the vertical line associated to pure capacitive charge of the capacitor, Fig. 5D (inset). EDRs of 0.38, 0.69 and $4.82 \mathrm{ohms}$ have been measured for L-Y-900, L-B-900 and ACJM, respectively, pointing out the huge impact in the cell resistance (which is the sum of all the mentioned resistances) of an improved pore connectivity, as well as the importance of the presence of mesoporosity close to the microporosity that can act as ion reservoirs.

The impact of the lower resistance of the HPC electrodes in the performance of the capacitor was evaluated by estimation of the relationship between energy and power of the capacitors. Fig. 6 presents the Ragone plots of the symmetric cells. It can be seen that ACJM has a better performance in terms of energy when the capacitor works at low power demand $\left(9.9 \mathrm{Wh} \mathrm{kg}^{-1}\right.$ at $0.53 \mathrm{~kW} \mathrm{~kg}^{-1}$ for ACJM vs 2.9 and $4.8 \mathrm{Wh} \mathrm{kg}^{-1}$ at same power for the HPCs). This difference is notoriously reduced when a higher power output is demanded. The better energy retention response of HPCs is based on the higher capacitance retention (48 and 44\% for L-Y-900 and LB-900 and only $23 \%$ for ACJM when increasing the specific current from 1 to $64 \mathrm{~A} \mathrm{~g}^{-1}$ ), highlighting the benefits of the hierarchical porosity of these carbon materials. In this sense, the energy delivered by HPC-based devices are higher than that of ACJM for fast discharge times (less than one second, Fig. 6).

\subsubsection{Design of the asymmetric capacitors}

The electrochemical characterization (Section 3.2) revealed that HPCs could safely operate at loading voltages of $1.4 \mathrm{~V}$ for L-Y-900 and $1.5 \mathrm{~V}$ in the case of L-B-900. For ensuring that the capacitor cell will be safely working at such high voltage, it will be necessary to optimize the mass ratio between the electrodes in order to improve their performance [10,11].

Electrochemical stable potential windows were determined for both electrodes, with the selected windows being shown in Fig. S2, and then, the capacitance values were obtained from GCD curves at $2 \mathrm{~A} \mathrm{~g} \mathrm{~g}^{-1}$ that were measured on the same positive and negative electrode potential windows (Fig. 4). By equating the charge of both electrodes and fixing the potential windows of both electrodes, Equation 1 allowed to determine the optimized mass ratio of the electrodes. 
$w_{+} / w_{-}=C_{S P_{-}} \cdot\left|\Delta U_{-}\right| /\left(C_{S P_{+}} \cdot \Delta U_{+}\right)$

Were $\mathrm{w}_{+}$corresponds to the mass of the positive electrode, $\mathrm{w}_{-}$corresponds to the mass of the negative electrode, $\mathrm{C}_{\mathrm{SP} \text { - }}$ and $\mathrm{C}_{\mathrm{SP}+}$ correspond to the capacitance measured in the positive voltage of operation of the negative electrode and positive electrode respectively, and $\Delta \mathrm{U}_{+}$and $\Delta \mathrm{U}_{\text {. }}$ correspond to the potential interval of the positive electrode and negative electrode respectively.

Capacitance values for L-Y-900 (+) and L-Y-900(-) calculated between $0.27 \mathrm{~V}$ and $1.0 \mathrm{~V}$ and between $-0.4 \mathrm{~V}$ and $0.27 \mathrm{~V}$ were $98 \mathrm{~F} \mathrm{~g}^{-1}$ and $112 \mathrm{~F} \mathrm{~g}^{-1}$, respectively. Using these data and the Equation 1, an optimized mass ratio of $1.60\left(\mathrm{~m}_{+} / \mathrm{m}_{-}\right)$was obtained and used in the construction of the L-Y-900 asymmetric capacitor. Concerning the asymmetric capacitor based on L-B-900, the same procedure was used to get the mass ratio in the design of the capacitor. Capacitance values of $131 \mathrm{~F} \mathrm{~g}^{-1}$ and $137 \mathrm{~F} \mathrm{~g}^{-1}$ were determined between $0.31 \mathrm{~V}$ and $1.0 \mathrm{~V}$ and between $-0.5 \mathrm{~V}$ and $0.31 \mathrm{~V}$, respectively. The asymmetric L-B-900 capacitor was then assembled with the optimized mass ratio of 1.25 . Fig. 7 provides evidences of the electrochemical stability of the asymmetric capacitors. The CVs recorded with increasing cut-off voltages barely reveals the appearance of faradaic currents at the upper limits of the CVs, being only relevant at $1.5 \mathrm{~V}$ in LB-900 capacitor (red line, Fig. 7A). Coulombic efficiencies of 98, 98 and 97\% were registered at $1.2,1.4$ and $1.5 \mathrm{~V}$, respectively, demonstrating a good stability of the asymmetric capacitor. Gravimetric capacitance increased with voltage from 26 to 28 and finally $30 \mathrm{~F} \mathrm{~g}^{-1}$. This increase can be connected to the electrochemical hydrogen storage on the negative electrode, which caused a noticeable increment in capacitance when the potential of the electrode reaches values close to $-0.5 \mathrm{~V}$, Fig. 2. In the case of L-Y-900, the CV (Fig. 7B) demonstrated a negative relationship between the cut-off voltage and the capacitance (values of 25,24 and $22 \mathrm{~F} \mathrm{~g}^{-1}$ at 1.0 , 1.2 and $1.4 \mathrm{~V}$, respectively) due to the decrease in capacitance of the positive electrode, a feature previously shown in Fig. 2. A good stability of the asymmetric capacitor has been also achieved in this case, with the coulombic efficiency being higher than $97 \%$ at $1.4 \mathrm{~V}$.

The high stabilities of the capacitors are justified by the careful design of the system that allows to control the potential windows for each electrode, as pointed out in Fig. 7. It can be seen that the electrodes were indeed working very close to the intended potential intervals, with a 
deviation of $30 \mathrm{mV}$ towards less positive potentials in the case of L-B-900 (Fig. 7A), and towards more positive potentials in the case of L-Y-900 (Fig. 7B).

The performance of the asymmetric configuration is compared to the symmetric L-B-900 capacitor and also to that of the symmetric commercial activated carbon capacitor, ACJM, in Table 2. The parameters listed in the table have been measured at constant power $\left(1.3 \mathrm{~kW} \mathrm{~kg}^{-1}\right)$. It is seen again the higher capacitance of ACJM, which is translated into a higher energy density. Nevertheless, the L-B-900 cell has a better energetic efficiency (which is defined as the ratio between the recovered energy and the energy employed in charging the system) thanks to its lower cell resistance. When the capacitor is constructed following the asymmetric in weight design, the capacitor performs similarly to the symmetric capacitor when a voltage window of $1.2 \mathrm{~V}$ is used. When the voltage is increased to $1.4 \mathrm{~V}$ an increase in energy density higher than $35 \%$ is obtained with respect to the symmetric capacitor with similar energetic and coulombic efficiencies. Finally, the voltage can still be increased up to $1.5 \mathrm{~V}$ while maintaining an adequate performance, although the obtained energy increase is only of $9 \%$. In all the cases, symmetric or asymmetric capacitors, their performance in terms of energetic efficiencies is around $10 \%$ better than the symmetric capacitor built with the ACJM commercial sample.

The power characteristics of the L-B-900 and the L-Y-900 asymmetric capacitors were also evaluated, since the increase in energy could have been followed by a drop in the rate performance of the system. Ragone plots in Fig. 6 clearly demonstrate the opposite. The L-B900 asymmetric capacitor does not only performs better in terms of energy density but it also keeps the high power characteristics inherent to the use of HPC electrodes. The maximum power of the devices has been determined to be $52.7 \mathrm{~kW} \mathrm{~kg}^{-1}$ using the equation $P=$ $V^{2} / 4 \cdot R_{c e l l} \cdot\left(w_{+}+w_{-}\right)$. The energy vs power curves of L-B-900 and ACJM now intersect at $3.1 \mathrm{~kW} \mathrm{~kg}^{-1}$ and $5.2 \mathrm{Wh} \mathrm{kg}^{-1}$, and therefore the asymmetric capacitor will deliver more energy than the capacitor assembled with the commercial activated carbon at discharge times lower than 6 seconds. This is a remarkable result taking into account the important differences in surface areas between these carbon materials employed as electrodes and the origin of the HPC (prepared using a by-product like lignin). On the other hand, the L-Y-900 asymmetric capacitor achieves a higher energy density at the cost of losing capacitance retention at high power rates. The cell resistance in this case was around $9 \Omega$, more than 4 times higher than in the symmetric 
design. This undesired result is probably related to the increased thickness of the positive electrode (a mandatory feature dictated by the asymmetric in mass design), which is close to 280 $\mu \mathrm{m}$ in this case, and also to the high concentration of surface oxygen groups.

\subsubsection{Durability tests}

The effect of the asymmetric design in the durability of the L-B-900 cell has been studied at three different voltages, $1.2,1.4$ and $1.5 \mathrm{~V}$. Durability tests are usually conducted using potentiostatic or continuous cycling galvanostatic conditions, namely floating/ holding voltage and cyclability tests [55]. Previous studies have demonstrated that these tests are not comparable even when they are accomplished using the same cut-off voltage [56], since the conditions employed in floating tests are harsher and can compromise the integrity of other cell components (like the collectors or the separators) rather than that of the carbon materials employed in the electrodes. In consequence, the cell components must be carefully optimized in order to be able to observe the true performance of the electrode materials, and it is possible to find examples in the literature about the use of additives in the electrolyte [56,57] or pretreatments of the electrodes [58] for achieving such purpose. Since floating tests can be envisaged as accelerated cyclability tests [55], we have opted to submit the asymmetric supercapacitors to a long cyclability test in our case, considering the reactivity of acidic aqueous electrolyte and that we have not added any compound to minimize the deterioration of the cell components.

The durability tests consisted in a continuous galvanostatic charge-discharge experiment at $1 \mathrm{~A}$ $\mathrm{g}^{-1}$ for 5000 cycles. In these tests, stainless steel has been substituted by titanium as the material of choice for the collectors, since the initial tests showed the degradation of the positive collector in the capacitors operating at cut-offs values higher than $1.2 \mathrm{~V}$. The same test has been conducted in symmetric L-B-900 and ACJM cells for comparison purposes. The capacitance versus the number of cycles is presented in Figure 8. As can be seen, the retention of capacitance for the asymmetric L-B-900 capacitor is around $87 \%$ at $1.4 \mathrm{~V}$, while loading the capacitor up to $1.5 \mathrm{~V}$ was found to be harmful for the stability of the capacitor (retention of capacitance of only 63\%). This result, along with the minor impact on gained energy when compared to $1.4 \mathrm{~V}$, Table 2 and Figure 11, renders inadequate the use of $1.5 \mathrm{~V}$ in this device. A neutral electrolyte is better suited for achieving higher voltages $[59,60]$. Even so, the advantages 
of asymmetric design in the durability of cells can be seen when one compares the capacitance of the symmetric and asymmetric capacitors working at $1.2 \mathrm{~V}$, red and green lines respectively in Figure 8. The retention of capacitance of the asymmetric cell is close to $100 \%$, while for the symmetric it is $95 \%$ at the end of the test. Finally, the commercial activated carbon supercapacitor showed a worse capacitance retention than both symmetric and asymmetric L-B900 devices, with a capacitance retention of $83 \%$ after 5000 cycles.

\section{Conclusions}

In this work, hierarchical porous carbons (HPCs) were synthesized by using a green and simple method, which consisted of the impregnation of zeolites ( $\mathrm{Y}$ and Beta) with lignin solutions as carbon precursors. These HPCs showed a pore structure and mesopore size dependent on template. Both HPCs displayed a similar microporosity but different mesoporosity, being larger in volume and in pore size in the case of L-B-900. Moreover, these carbon materials presented a rich oxygen surface chemistry which are a consequence of the interaction between the zeolite and the lignin during the carbonization process.

L-B-900 and L-Y-900 were electrochemically characterized in a three electrode T-type Swagelock cell in acid medium. L-B-900 sample showed a quasi-rectangular shape voltammogram, which is attributed to capacitive process, with a small pseudocapacitance contribution at around $0.3 \mathrm{~V}$. However, in the case of L-Y-900 sample, the pseudocapacitance process associated to CO-type surface groups is much more important, in agreement with the much higher concentration of surface oxygen. Both HPCs displayed good stability towards negative and positive potential limit, which led to the preparation of asymmetric capacitor with a high potential window stability.

Symmetric capacitors based on both L-Y-900 and L-B-900 samples showed better performance in terms of energy at high power demand than a device prepared from activated commercial carbon. This behavior is due to the hierarchical porosity of these carbon materials. Regarding the asymmetric capacitors, the device prepared with L-Y-900 gave rise to a potential window of 1.4 $\mathrm{V}$, while L-B-900 reached 1.5 V. Both asymmetric devices had better performance in terms of energy density than the symmetric counterpart. In addition, the L-B-900 asymmetric device showed a comparable energy density, but a higher energetic efficiency and rate performance than 
a symmetric device made using a commercial activated commercial carbon for supercapacitors which have more than twice the surface area of the HPCs. Durability test revealed that the stability of the capacitors is also improved when the asymmetric concept is used. The results from these tests show that L-B-900 capacitor is able to operate safely at $1.4 \mathrm{~V}$. This remarkable result points out the viability of lignin as a low cost, renewable, and reliable source for the production of carbon electrodes for supercapacitors.

\section{Acknowledgements}

The authors would like to thank MINECO (CTQ2015-66080-R, MAT2013-42007-P) and Generalitat Valenciana and FEDER (PROMETEO/2013/038 and PROMETEOII/2014/010) for the financial support. RRR thanks MINECO for a 'Juan de la Cierva' contract (JCI-2012-12664).

\section{References}

[1] A.G. Pandolfo, A.F. Hollenkamp, Carbon properties and their role in supercapacitors, Journal of Power Sources 157 (2006) 11-27.

[2] B.E. Conway, Electrochemical Supercapacitors: Scientific Fundamentals and Technological Applications, Kluwer-Plenum Press, New York, 1999.

[3] V. Khomenko, E. Raymundo-Piñero, F. Béguin, A new type of high energy asymmetric capacitor with nanoporous carbon electrodes in aqueous electrolyte, Journal of Power Sources 195 (2010) 4234-4241.

[4] M.J. Mostazo-López, R. Ruiz-Rosas, E. Morallón, D. Cazorla-Amorós, Generation of nitrogen functionalities on activated carbons by amidation reactions and Hofmann rearrangement: Chemical and electrochemical characterization, Carbon 91 (2015) 252-265.

[5] C. González-Gaitán, R. Ruiz-Rosas, H. Nishihara, T. Kyotani, E. Morallón, D. CazorlaAmorós, Successful functionalization of superporous zeolite templated carbon using aminobenzene acids and electrochemical methods, Carbon 99 (2016) 157-166.

[6] R. Berenguer, R. Ruiz-Rosas, A. Gallardo, D. Cazorla-Amorós, E. Morallón, H. Nishihara, et al., Enhanced electro-oxidation resistance of carbon electrodes induced by phosphorus surface groups, Carbon 95 (2015) 681-689.

[7] D. Salinas-Torres, J.M. Sieben, D. Lozano-Castelló, D. Cazorla-Amorós, E. Morallón, Asymmetric hybrid capacitors based on activated carbon and activated carbon fibre-PANI electrodes, Electrochimica Acta 89 (2013) 326-333.

[8] M.J. Bleda-Martínez, J.M. Pérez, A. Linares-Solano, E. Morallón, D. Cazorla-Amorós, Effect of surface chemistry on electrochemical storage of hydrogen in porous carbon materials, Carbon 46 (2008) 1053-1059. 
[9] J. Zhang, X.S. Zhao, On the configuration of supercapacitors for maximizing electrochemical performance, ChemSusChem 5 (2012) 818-841.

[10] C. Peng, S. Zhang, X. Zhou, G.Z. Chen, Unequalisation of electrode capacitances for enhanced energy capacity in asymmetrical supercapacitors, Energy \& Environmental Science 3 (2010) 1499-1502.

[11] J.H. Chae, G.Z. Chen, 1.9 V aqueous carbon-carbon supercapacitors with unequal electrode capacitances, Electrochimica Acta 86 (2012) 248-254.

[12] H. Nishihara, T. Kyotani, Templated Nanocarbons for Energy Storage, Advanced Materials 24 (2012) 4473-4498.

[13] H. Jiang, P.S. Lee, C. Li, 3D carbon based nanostructures for advanced supercapacitors, Energy \& Environmental Science 6 (2012) 41-53.

[14] T. Kyotani, T. Nagai, S. Inoue, A. Tomita, Formation of New Type of Porous Carbon by Carbonization in Zeolite Nanochannels, Chemistry of Materials 9 (1997) 609-615.

[15] J. Rodriguez-Mirasol, T. Cordero, L.R. Radovic, J.J. Rodriguez, Structural and Textural Properties of Pyrolytic Carbon Formed within a Microporous Zeolite Template, Chemistry of Materials 10 (1998) 550-558.

[16] H. Itoi, H. Nishihara, T. Kogure, T. Kyotani, Three-Dimensionally Arrayed and Mutually Connected 1.2-nm Nanopores for High-Performance Electric Double Layer Capacitor, Journal of the American Chemical Society 133 (2011) 1165-1167.

[17] W. Xing, S.Z. Qiao, R.G. Ding, F. Li, G.Q. Lu, Z.F. Yan, et al., Superior electric double layer capacitors using ordered mesoporous carbons, Carbon 44 (2006) 216-224.

[18] D.-W. Wang, F. Li, M. Liu, G.Q. Lu, H.-M. Cheng, 3D Aperiodic Hierarchical Porous Graphitic Carbon Material for High-Rate Electrochemical Capacitive Energy Storage, Angewandte Chemie International Edition 47 (2008) 373-376.

[19] M.-M. Titirici, R.J. White, N. Brun, V.L. Budarin, D.S. Su, F. del Monte, et al., Sustainable carbon materials, Chemical Society Reviews 44 (2015) 250-290.

[20] J.M. Rosas, R. Berenguer, M.J. Valero-Romero, J. Rodríguez-Mirasol, T. Cordero, Preparation of different carbon materials by thermochemical conversion of lignin, Frontiers in Materials | Carbon-based Materials 1 (2014) 29.

[21] A.J. Ragauskas, G.T. Beckham, M.J. Biddy, R. Chandra, F. Chen, M.F. Davis, et al., Lignin Valorization: Improving Lignin Processing in the Biorefinery, Science 344 (2014) 1246843.

[22] J. Rodríguez-Mirasol, T. Cordero, J.J. Rodríguez, Preparation and characterization of activated carbons from eucalyptus kraft lignin, Carbon 31 (1993) 87-95.

[23] E. Gonzalez-Serrano, T. Cordero, J. Rodriguez-Mirasol, L. Cotoruelo, J.J. Rodriguez, Removal of water pollutants with activated carbons prepared from H 3PO4 activation of lignin from kraft black liquors, Water Research 38 (2004) 3043-3050.

[24] J. Rodríguez-Mirasol, T. Cordero, J.J. Rodríguez, High-temperature carbons from kraft lignin, Carbon 34 (1996) 43-52.

[25] J. Kadla, S. Kubo, R. Venditti, R. Gilbert, A. Compere, W. Griffith, Lignin-based carbon fibers for composite fiber applications, Carbon 40 (2002) 2913-2920. 
[26] D.A. Baker, T.G. Rials, Recent advances in low-cost carbon fiber manufacture from lignin, Journal of Applied Polymer Science 130 (2013) 713-728

[27] M. Lallave, J. Bedia, R. Ruiz-Rosas, J. Rodríguez-Mirasol, T. Cordero, J.C. Otero, et al., Filled and Hollow Carbon Nanofibers by Coaxial Electrospinning of Alcell Lignin without Binder Polymers, Advanced Materials 19 (2007) 4292-4296.

[28] R. Ruiz-Rosas, J. Bedia, M. Lallave, I.G. Loscertales, A. Barrero, J. Rodríguez-Mirasol, et al., The production of submicron diameter carbon fibers by the electrospinning of lignin, Carbon 48 (2010) 696-705.

[29] Sabornie Chatterjee, Tomonori Saito, Orlando Rios, Alexander Johs, Lignin Based Carbon Materials for Energy Storage Applications, in: Green Technologies for the Environment, American Chemical Society, 2014: pp. 203-218. http://dx.doi.org/10.1021/bk-20141186.ch011 (accessed December 6, 2015).

[30] A.M. Navarro-Suárez, J. Carretero-González, V. Roddatis, E. Goikolea, J. Ségalini, E. Redondo, et al., Nanoporous carbons from natural lignin: study of structural-textural properties and application to organic-based supercapacitors, RSC Advances 4 (2014) 48336-48343.

[31] D. Saha, Y. Li, Z. Bi, J. Chen, J.K. Keum, D.K. Hensley, et al., Studies on Supercapacitor Electrode Material from Activated Lignin-Derived Mesoporous Carbon, Langmuir 30 (2014) 900-910.

[32] J.-W. Jeon, L. Zhang, J.L. Lutkenhaus, D.D. Laskar, J.P. Lemmon, D. Choi, et al., Controlling Porosity in Lignin-Derived Nanoporous Carbon for Supercapacitor Applications, ChemSusChem 8 (2015) 428-432.

[33] W. Zhang, H. Lin, Z. Lin, J. Yin, H. Lu, D. Liu, et al., 3 D Hierarchical Porous Carbon for Supercapacitors Prepared from Lignin through a Facile Template-Free Method, ChemSusChem 8 (2015) 2114-2122.

[34] W. Zhang, M. Zhao, R. Liu, X. Wang, H. Lin, Hierarchical porous carbon derived from lignin for high performance supercapacitor, Colloids and Surfaces A: Physicochemical and Engineering Aspects 484 (2015) 518-527.

[35] C. Lai, Z. Zhou, L. Zhang, X. Wang, Q. Zhou, Y. Zhao, et al., Free-standing and mechanically flexible mats consisting of electrospun carbon nanofibers made from a natural product of alkali lignin as binder-free electrodes for high-performance supercapacitors, Journal of Power Sources 247 (2014) 134-141.

[36] R. Berenguer, F.J. García-Mateos, R. Ruiz-Rosas, D. Cazorla-Amorós, E. Morallón, J. Rodríguez-Mirasol, et al., Biomass-derived binderless fibrous carbon electrodes for ultrafast energy storage, Green Chemistry (2015).

[37] S. Hu, S. Zhang, N. Pan, Y.-L. Hsieh, High energy density supercapacitors from lignin derived submicron activated carbon fibers in aqueous electrolytes, Journal of Power Sources 270 (2014) 106-112.

[38] M.J. Valero-Romero, E.M. Márquez-Franco, J. Bedia, J. Rodríguez-Mirasol, T. Cordero, Hierarchical porous carbons by liquid phase impregnation of zeolite templates with lignin solution, Microporous and Mesoporous Materials 196 (2014) 68-78. 
[39] R. Ruiz-Rosas, M.J. Valero-Romero, D. Salinas-Torres, J. Rodríguez-Mirasol, T. Cordero, E. Morallón, et al., Electrochemical Performance of Hierarchical Porous Carbon Materials Obtained from the Infiltration of Lignin into Zeolite Templates, ChemSusChem 7 (2014) 1458-1467.

[40] J. Jagiello, J.P. Olivier, 2D-NLDFT adsorption models for carbon slit-shaped pores with surface energetical heterogeneity and geometrical corrugation, Carbon 55 (2013) 70-80.

[41] M.J. Bleda-Martínez, J.A. Maciá-Agulló, D. Lozano-Castelló, E. Morallón, D. CazorlaAmorós, A. Linares-Solano, Role of surface chemistry on electric double layer capacitance of carbon materials, Carbon 43 (2005) 2677-2684.

[42] O. Ornelas, J.M. Sieben, R. Ruiz-Rosas, E. Morallón, D. Cazorla-Amorós, J. Geng, et al., On the origin of the high capacitance of nitrogen-containing carbon nanotubes in acidic and alkaline electrolytes, Chemical Communications 50 (2014) 11343-11346.

[43] M.C. Román-Martínez, D. Cazorla-Amorós, A. Linares-Solano, C.S.-M. de Lecea, Tpd and TPR characterization of carbonaceous supports and Pt/C catalysts, Carbon 31 (1993) 895902.

[44] J.. Figueiredo, M.F.. Pereira, M.M.. Freitas, J.J.. Órfão, Modification of the surface chemistry of activated carbons, Carbon 37 (1999) 1379-1389.

[45] R. Berenguer, H. Nishihara, H. Itoi, T. Ishii, E. Morallón, D. Cazorla-Amorós, et al., Electrochemical generation of oxygen-containing groups in an ordered microporous zeolitetemplated carbon, Carbon 54 (2013) 94-104.

[46] P.-Z. Cheng, H. Teng, Electrochemical responses from surface oxides present on HNO3treated carbons, Carbon 41 (2003) 2057-2063.

[47] C.O. Ania, V. Khomenko, E. Raymundo-Piñero, J.B. Parra, F. Béguin, The Large Electrochemical Capacitance of Microporous Doped Carbon Obtained by Using a Zeolite Template, Advanced Functional Materials 17 (2007) 1828-1836.

[48] H. Itoi, H. Nishihara, T. Ishii, K. Nueangnoraj, R. Berenguer-Betri\&aacute;n, T. Kyotani, Large Pseudocapacitance in Quinone-Functionalized Zeolite-Templated Carbon, Bulletin of the Chemical Society of Japan 87 (2014) 250-257.

[49] D. Cazorla-Amorós, D. Lozano-Castelló, E. Morallón, M.J. Bleda-Martínez, A. LinaresSolano, S. Shiraishi, Measuring cycle efficiency and capacitance of chemically activated carbons in propylene carbonate, Carbon 48 (2010) 1451-1456.

[50] S. Leyva-García, K. Nueangnoraj, D. Lozano-Castelló, H. Nishihara, T. Kyotani, E. Morallón, et al., Characterization of a zeolite-templated carbon by electrochemical quartz crystal microbalance and in situ Raman spectroscopy, Carbon 89 (2015) 63-73.

[51] M.D. Stoller, R.S. Ruoff, Best practice methods for determining an electrode material's performance for ultracapacitors, Energy \& Environmental Science 3 (2010) 1294-1301.

[52] P. Kurzweil, A. Hildebrand, M. Weiß, Accelerated Life Testing of Double-Layer Capacitors: Reliability and Safety under Excess Voltage and Temperature, ChemElectroChem 2 (2015) 150-159. 
[53] S. Fletcher, V.J. Black, I. Kirkpatrick, A universal equivalent circuit for carbon-based supercapacitors, Journal of Solid State Electrochemistry 18 (2013) 1377-1387.

[54] R. Kötz, M. Carlen, Principles and applications of electrochemical capacitors, Electrochimica Acta 45 (2000) 2483-2498.

[55] D. Weingarth, A. Foelske-Schmitz, R. Kötz, Cycle versus voltage hold - Which is the better stability test for electrochemical double layer capacitors?, J. Power Sources. 225 (2013) 8488.

[56] P. Ratajczak, K. Jurewicz, P. Skowron, Q. Abbas, F. Béguin, Effect of accelerated ageing on the performance of high voltage carbon/carbon electrochemical capacitors in salt aqueous electrolyte, Electrochimica Acta. 130 (2014) 344-350.

[57] Q. Abbas, P. Ratajczak, P. Babuchowska, A.L. Comte, D. Bélanger, T. Brousse, et al., Strategies to Improve the Performance of Carbon/Carbon Capacitors in Salt Aqueous Electrolytes, J. Electrochem. Soc. 162 (2015) A5148-A5157.

[58] P. Jeżowski, M. Nowicki, M. Grzeszkowiak, R. Czajka, F. Béguin, Chemical etching of stainless steel 301 for improving performance of electrochemical capacitors in aqueous electrolyte, J. Power Sources. 279 (2015) 555-562.

[59] M.P. Bichat, E. Raymundo-Piñero, F. Béguin, High voltage supercapacitor built with seaweed carbons in neutral aqueous electrolyte, Carbon. 48 (2010) 4351-4361.

[60] I. Piñeiro-Prado, D. Salinas-Torres, R. Ruiz Rosas, E. Morallon, D. Cazorla-Amoros, Design of activated carbon/activated carbon asymmetric capacitors, Front. Mater. 3 (2016) 16. 
Table 1. Textural properties and surface chemistry of the carbon materials

\begin{tabular}{|c|c|c|c|c|c|c|}
\hline \multirow[b]{2}{*}{ Samples } & \multicolumn{3}{|c|}{ Textural properties } & \multicolumn{3}{|c|}{ Surface chemistry } \\
\hline & $\begin{array}{c}\mathbf{S}_{\text {BET }} \\
\left(\mathbf{m}^{2} \mathbf{g}^{-1}\right)\end{array}$ & $\begin{array}{c}V_{\mathrm{DR}} \\
\left(\mathrm{cm}^{3} \mathrm{~g}^{-1}\right)\end{array}$ & $\begin{array}{c}V_{\text {meso }} \\
\left(\mathrm{cm}^{3} \mathrm{~g}^{-1}\right)\end{array}$ & $\begin{array}{c}\text { CO } \\
\left.(\mu \mathrm{mol} \mathrm{g})^{-1}\right)\end{array}$ & $\begin{array}{c}\mathrm{CO}_{2} \\
\mathrm{umol} \mathrm{g}\end{array}$ & $\begin{array}{c}\mathbf{O} \\
\left(\mu \mathrm{mol} \mathrm{g} \mathbf{g}^{-1}\right)\end{array}$ \\
\hline L-Y-900 & 670 & 0.27 & 0.10 & 1310 & 470 & 2250 \\
\hline L-B-900 & 930 & 0.36 & 1.19 & 800 & 90 & 980 \\
\hline ACJM & 2180 & 0.93 & 0.06 & 1440 & 380 & 2200 \\
\hline
\end{tabular}

Table 2. ACJM and L-B-900 Capacitor performance parameters measured at specific power of $1.3 \mathrm{~kW} \mathrm{~kg}^{-1}$ in $1 \mathrm{M} \mathrm{H}_{2} \mathrm{SO}_{4}$ solution.

\begin{tabular}{|c|c|c|c|c|}
\hline Capacitor & $\begin{array}{c}\mathrm{Cg}_{\mathrm{g}} \\
\left(\mathrm{F} \mathrm{g}^{-1}\right)\end{array}$ & $\begin{array}{c}\text { Energy } \\
\left(\mathbf{W h} \cdot \mathbf{k g}^{-1}\right)\end{array}$ & $\begin{array}{c}\text { Coulombic } \\
\text { Efficiency } \\
(\%)\end{array}$ & $\begin{array}{c}\text { Energetic } \\
\text { efficiency } \\
(\%)\end{array}$ \\
\hline ACJM $1.2 \mathrm{~V}$ & 43 & 8.1 & 100 & 80 \\
\hline L-B-900 1.2V & 25 & 4.2 & 100 & 89 \\
\hline Asymmetric $1.2 \mathrm{~V}$ & 24 & 4.8 & 100 & 92 \\
\hline Asymmetric $1.4 \mathrm{~V}$ & 25 & 6.3 & 99 & 91 \\
\hline Asymmetric $1.5 \mathrm{~V}$ & 25 & 6.8 & 99 & 90 \\
\hline
\end{tabular}




\section{Figure captions.}

Figure 1. (A) Nitrogen adsorption-desorption isotherms at $-196{ }^{\circ} \mathrm{C}$ of powder $\mathrm{HPCs}$ and commercial activated carbon ACJM. (B) NLDFT Pore size distribution obtained from the respective nitrogen adsorption isotherms. The inset shows the PSD on the micropore region.

Figure 2. Steady state voltammograms at different potential ranges from the open circuit potential to lower potential limits and higher potential limits for (A) L-Y-900 electrode and (B) L-B-900 electrode. The respective specific capacitances of these electrodes are reported at different (C) lower and (D) higher potential limits. Scan rate: $5 \mathrm{mV} \mathrm{s}^{-1} .1 \mathrm{M} \mathrm{H}_{2} \mathrm{SO}_{4}$ solution.

Figure 3. Galvanostatic charge-discharge curves at $2 \mathrm{~A} \mathrm{~g}^{-1}$ for L-Y-900 and L-B-900 electrodes: (A) potential window of the positive electrodes (B) potential window of the negative electrodes. $1 \mathrm{M} \mathrm{H}_{2} \mathrm{SO}_{4}$ solution.

Figure 4. Specific capacitance at different current densities for the more positive and less positive potential windows for: (blue) L-Y-900 electrode and (red) L-B-900 electrode. 1M $\mathrm{H}_{2} \mathrm{SO}_{4}$ solution.

Figure 5. GCD profiles at different cut-off voltages for the symmetric capacitors prepared with the following materials: (A) L-Y-900, (B) L-B-900 and (C) ACJM. Specific current: $1 \mathrm{~A} \mathrm{~g}^{-1}$. (D) Nyquist plot derived from the EIS measurements of these capacitors at $0.05 \mathrm{~V}$ and a voltage amplitude of $10 \mathrm{mV}$ (RMS). $1 \mathrm{M} \mathrm{H}_{2} \mathrm{SO}_{4}$ solution.

Figure 6. Ragone plot recorded at $1.2 \mathrm{~V}$ for all the symmetric and asymmetric capacitors. $1 \mathrm{M}$ $\mathrm{H}_{2} \mathrm{SO}_{4}$ solution.

Figure 7. Cyclic voltammograms at different voltages for the asymmetric capacitors prepared with (A) L-B-900 and (B) L-Y-900 samples. Scan rate: $20 \mathrm{mV} \mathrm{s}^{-1}$. Galvanostatic chargedischarge at $2 \mathrm{~A} \mathrm{~g}^{-1}$ of the asymmetric capacitor prepared with (C) L-B-900 (1.5 V) and (D) L-Y$900(1.4 \mathrm{~V})$ samples and the potential reached by the positive and negative electrodes. $1 \mathrm{M} \mathrm{H}_{2} \mathrm{SO}_{4}$ solution.

Figure 8. GCD Durability tests of symmetric (cut-off voltage: $1.2 \mathrm{~V}$, red line) and asymmetric (1.2, 1.4 and $1.5 \mathrm{~V}$, green, blue and orange lines, respectively) L-B-900 capacitors. The symmetric ACJM capacitor (1.2 V, black line) is also included for comparison purposes. Specific current: $1 \mathrm{~A} \mathrm{~g}^{-1}$. $1 \mathrm{M} \mathrm{H}_{2} \mathrm{SO}_{4}$ solution. 

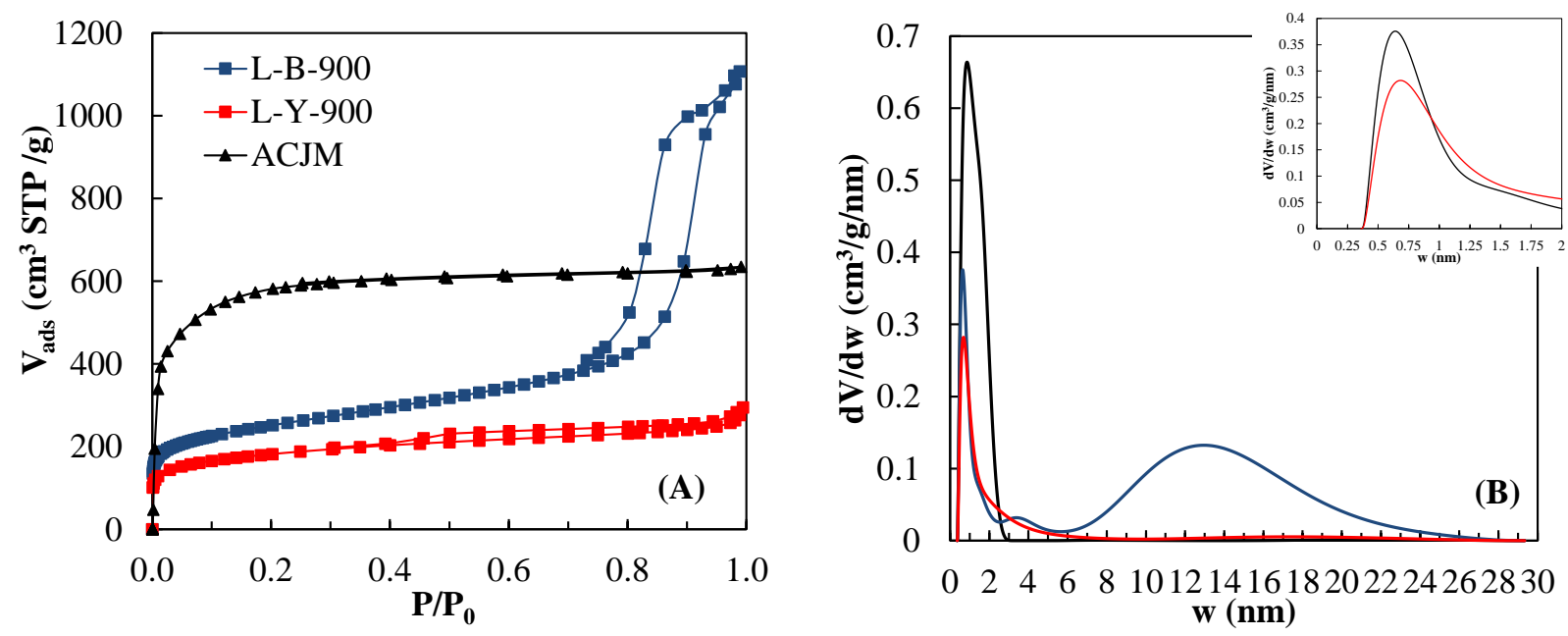

Figure 1. (A) Nitrogen adsorption-desorption isotherms at $-196{ }^{\circ} \mathrm{C}$ of powder $\mathrm{HPCs}$ and commercial activated carbon ACJM. (B) NLDFT Pore size distribution obtained from the respective nitrogen adsorption isotherms. The inset shows the PSD on the micropore region. 

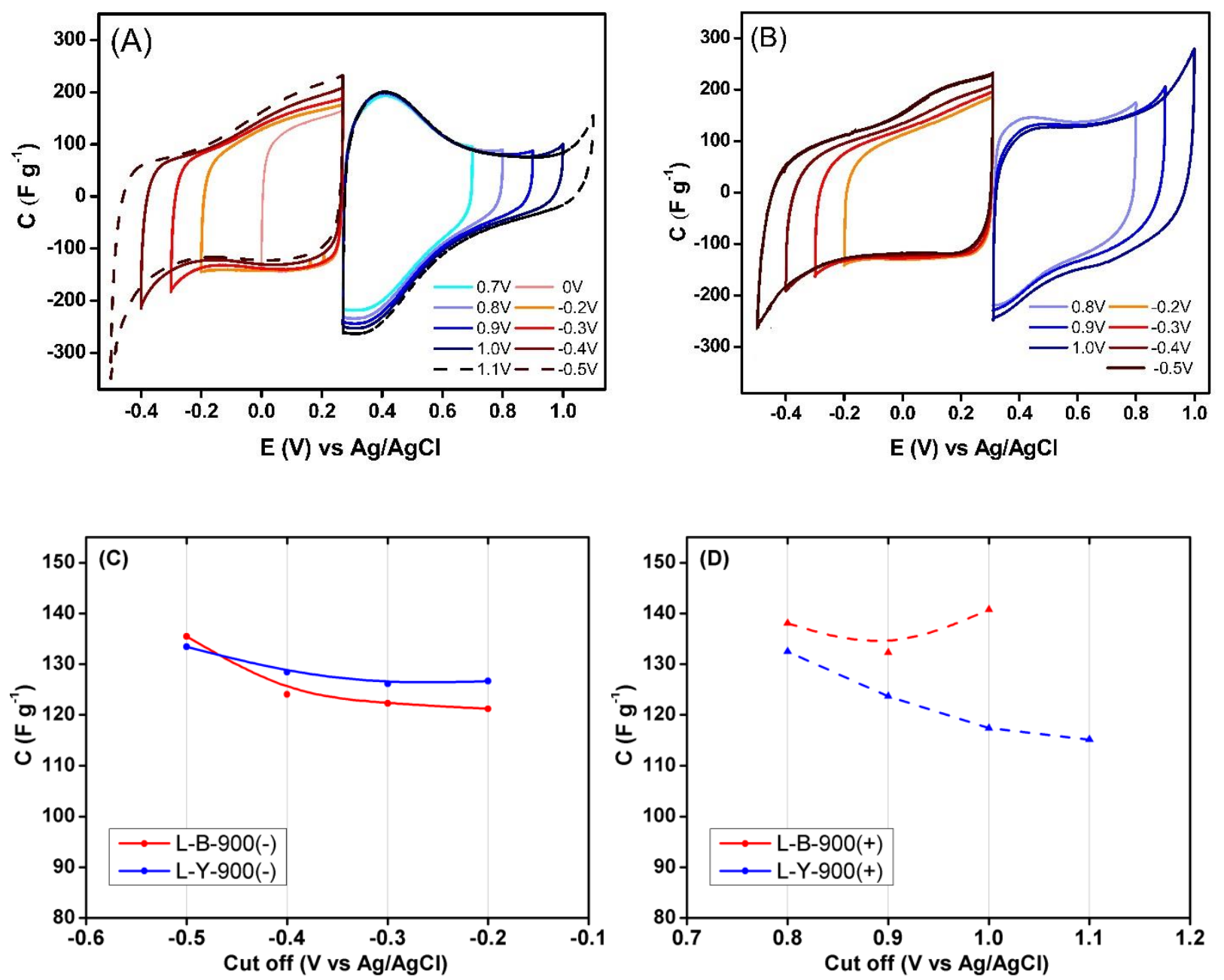

Figure 2. Steady state voltammograms at different potential ranges from the open circuit potential to lower potential limits and higher potential limits for (A) L-Y-900 electrode and (B) L-B-900 electrode. The respective specific capacitances of these electrodes are reported at different (C) lower and (D) higher potential limits. Scan rate: $5 \mathrm{mV} \mathrm{s}^{-1} .1 \mathrm{M} \mathrm{H}_{2} \mathrm{SO}_{4}$ solution. 

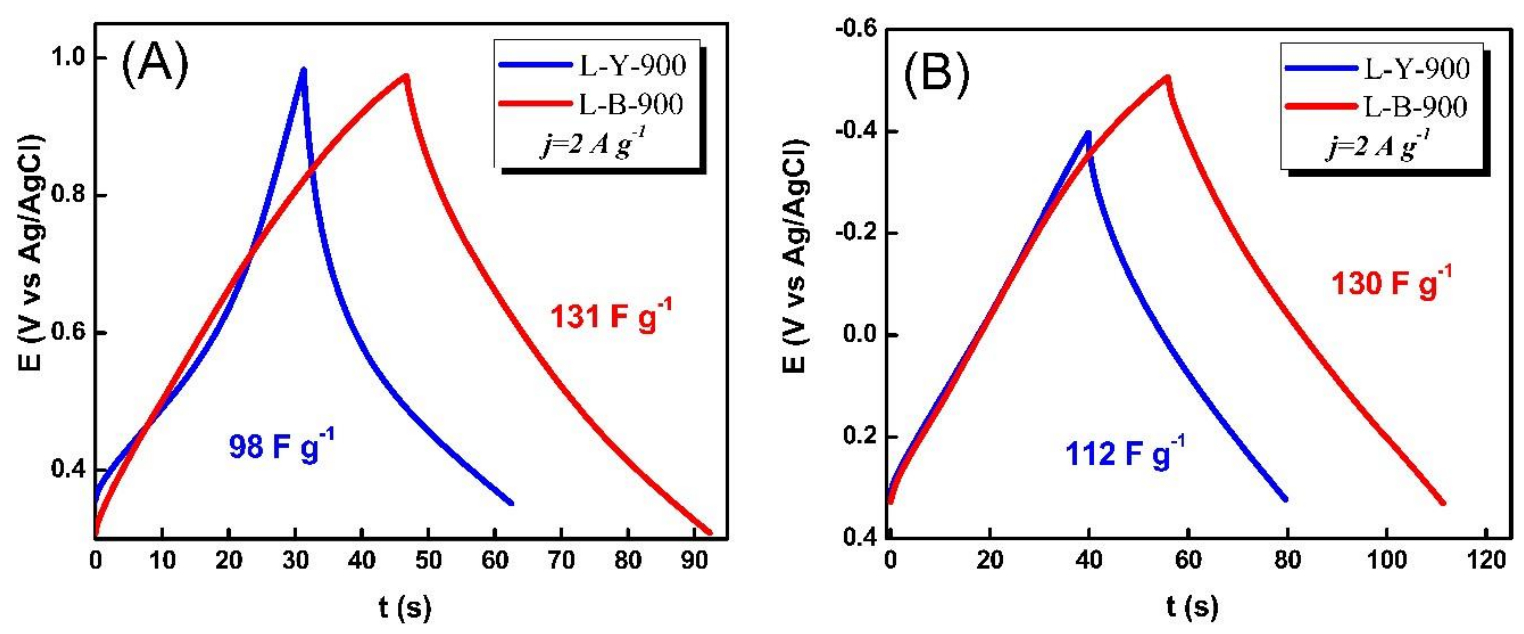

Figure 3. Galvanostatic charge-discharge curves at $2 \mathrm{~A} \mathrm{~g}^{-1}$ for L-Y-900 and L-B-900 electrodes: (A) potential window of the positive electrodes (B) potential window of the negative electrodes. $1 \mathrm{M} \mathrm{H}_{2} \mathrm{SO}_{4}$ solution. 


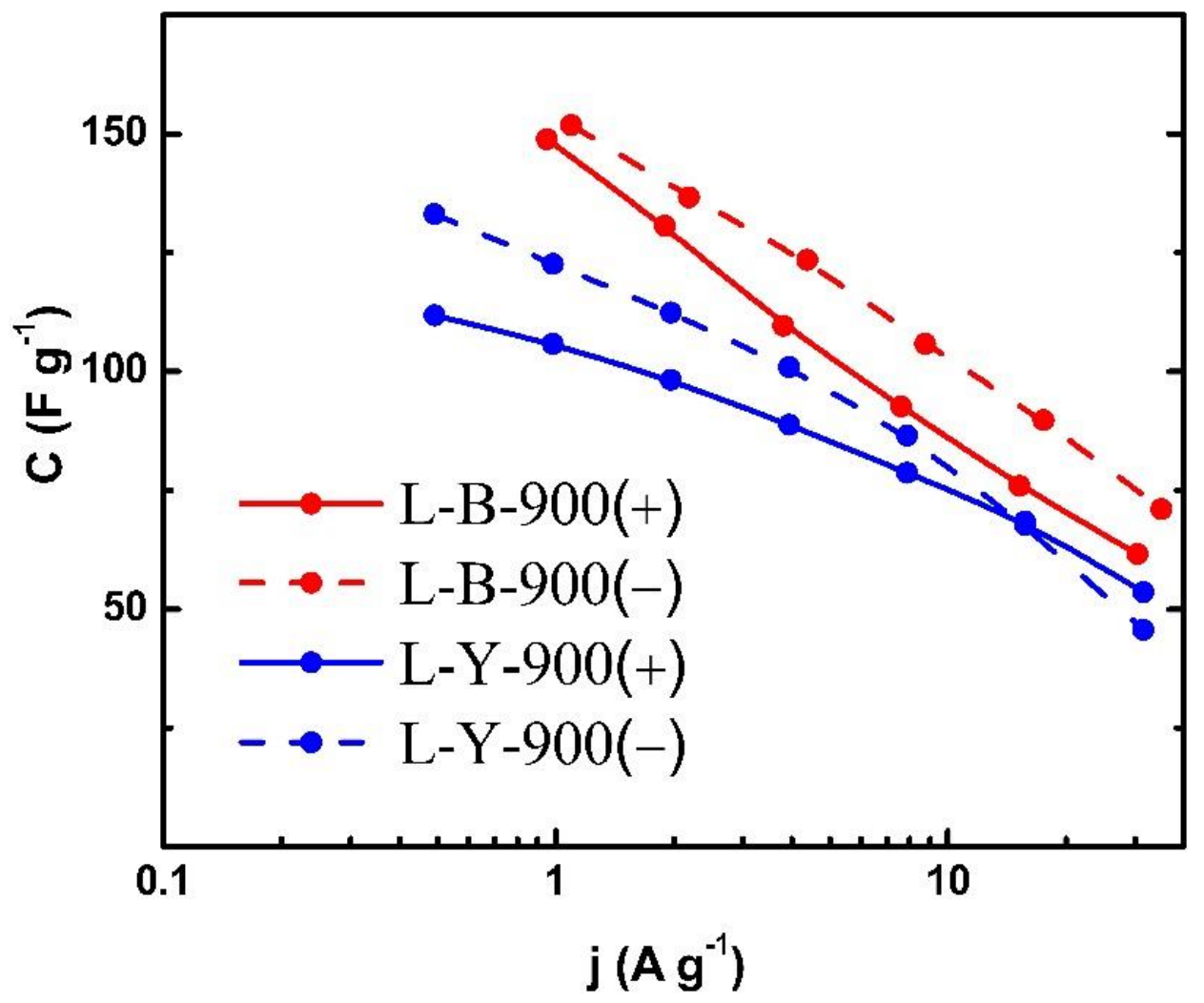

Figure 4. Specific capacitance at different current densities for the more positive and less positive potential windows for: (blue) L-Y-900 electrode and (red) L-B-900 electrode. 1M $\mathrm{H}_{2} \mathrm{SO}_{4}$ solution. 

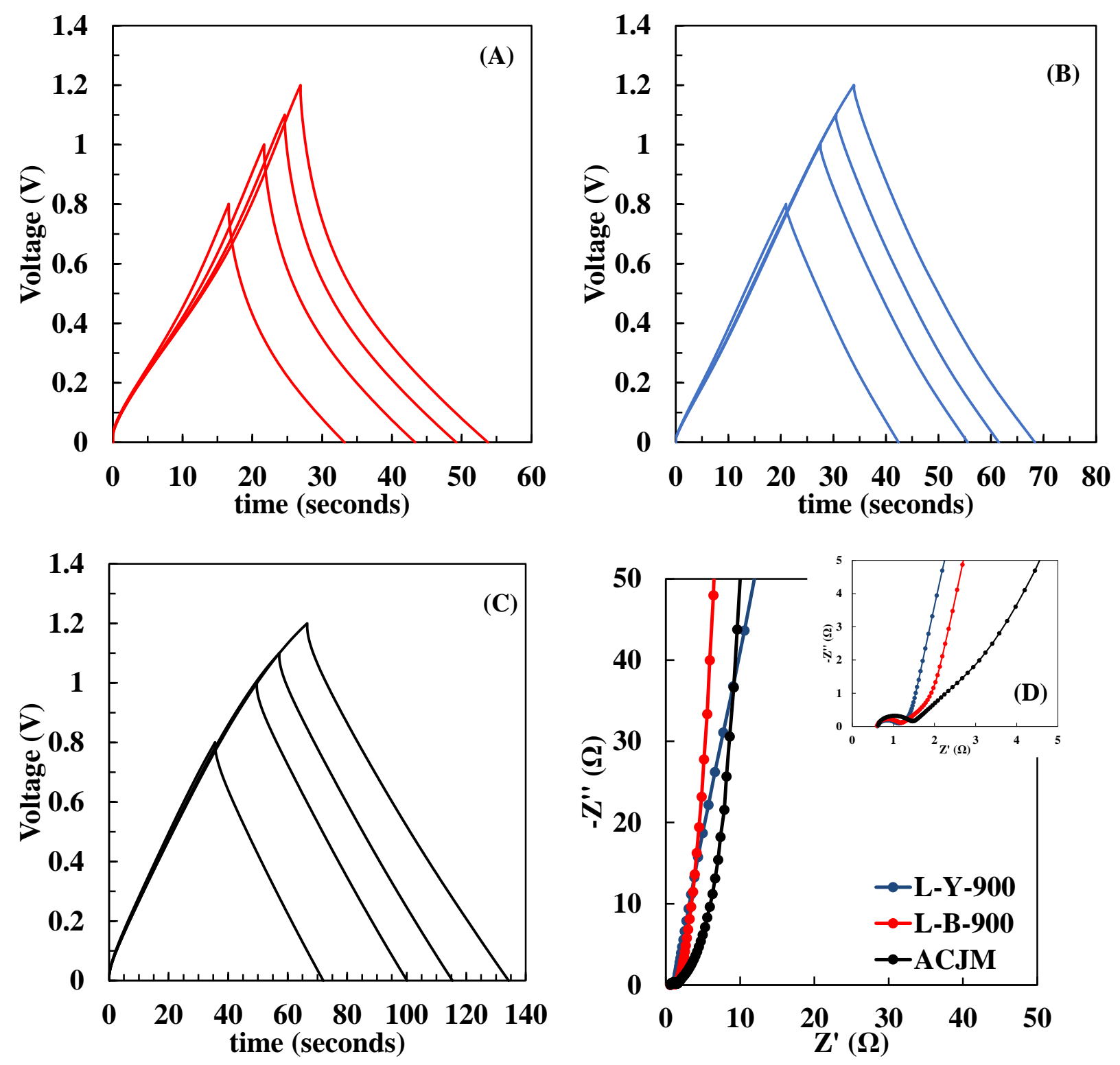

Figure 5. GCD profiles at different cut-off voltages for the symmetric capacitors prepared with the following materials: (A) L-Y-900, (B) L-B-900 and (C) ACJM. Specific current: 1 A g $^{-1}$. (D) Nyquist plot derived from the EIS measurements of these capacitors at $0.05 \mathrm{~V}$ and a voltage amplitude of $10 \mathrm{mV}$ (RMS). $1 \mathrm{M} \mathrm{H}_{2} \mathrm{SO}_{4}$ solution. 


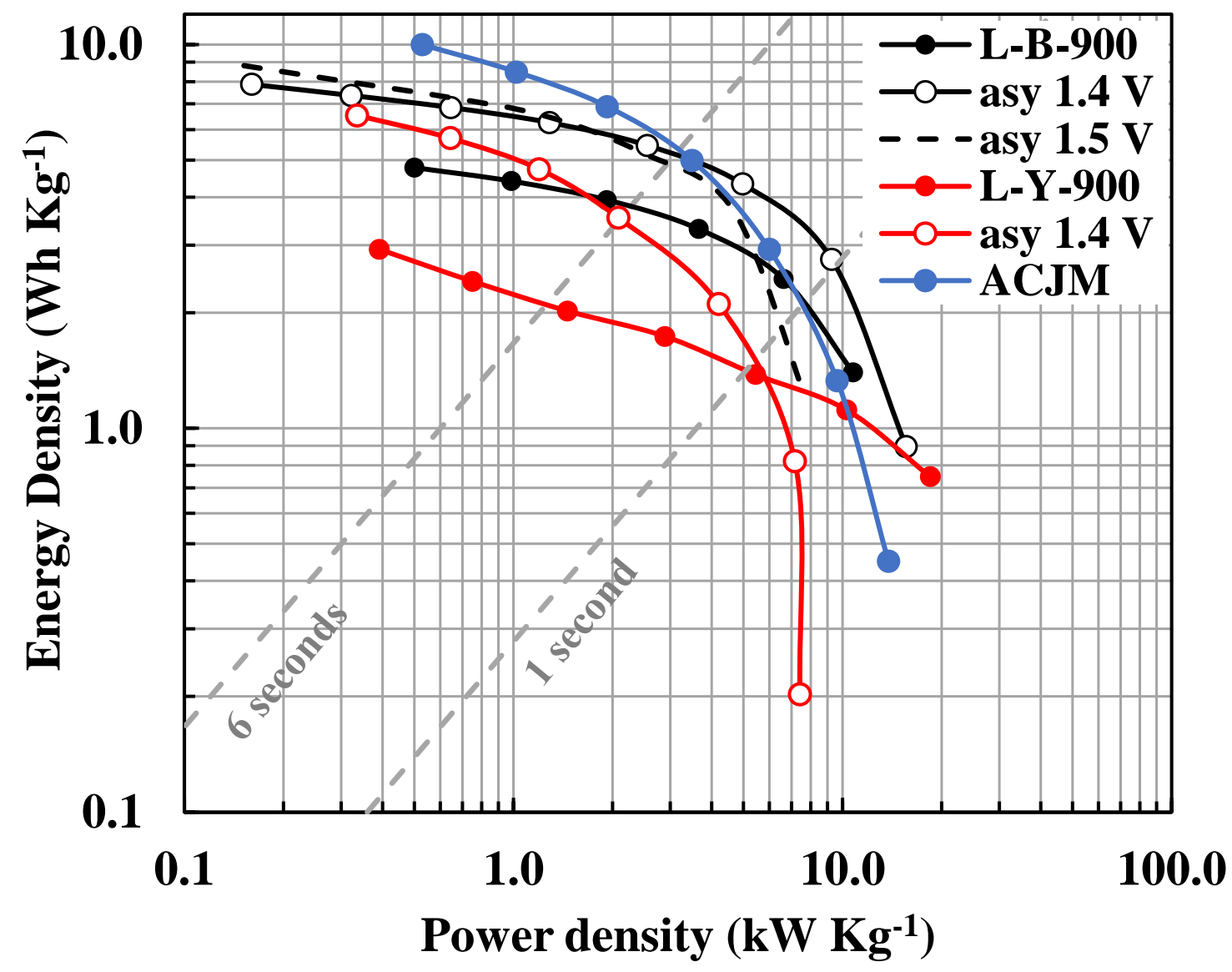

Figure 6. Ragone plot recorded at $1.2 \mathrm{~V}$ for all the symmetric and asymmetric capacitors. $1 \mathrm{M}$ $\mathrm{H}_{2} \mathrm{SO}_{4}$ solution. 

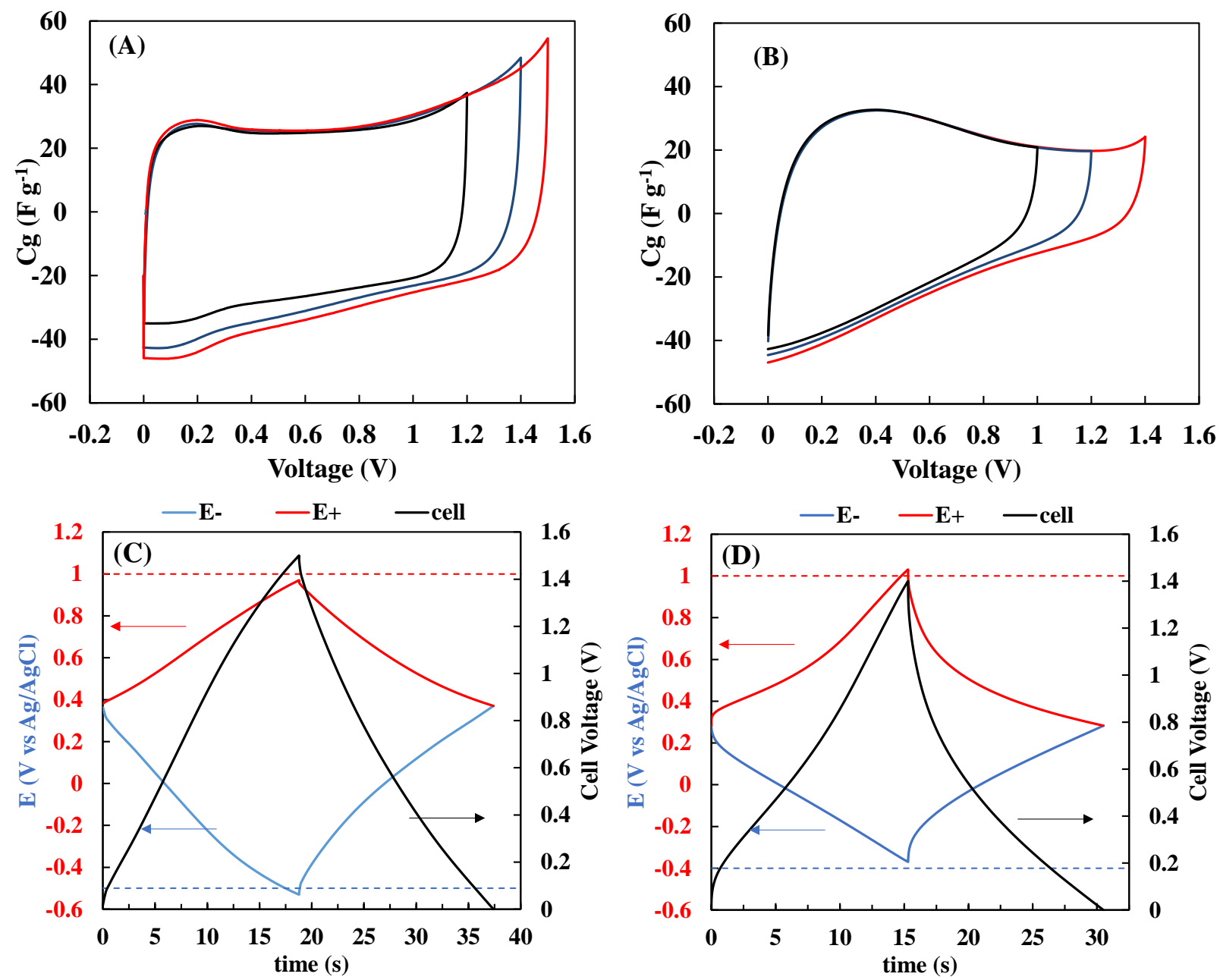

Figure 7. Cyclic voltammograms at different voltages for the asymmetric capacitors prepared with (A) L-B-900 and (B) L-Y-900 samples. Scan rate: $20 \mathrm{mV} \mathrm{s}^{-1}$. Galvanostatic chargedischarge at $2 \mathrm{~A} \mathrm{~g}^{-1}$ of the asymmetric capacitor prepared with (C) L-B-900 (1.5 V) and (D) L-Y$900(1.4 \mathrm{~V})$ samples and the potential reached by the positive and negative electrodes. $1 \mathrm{M} \mathrm{H}_{2} \mathrm{SO}_{4}$ solution. 


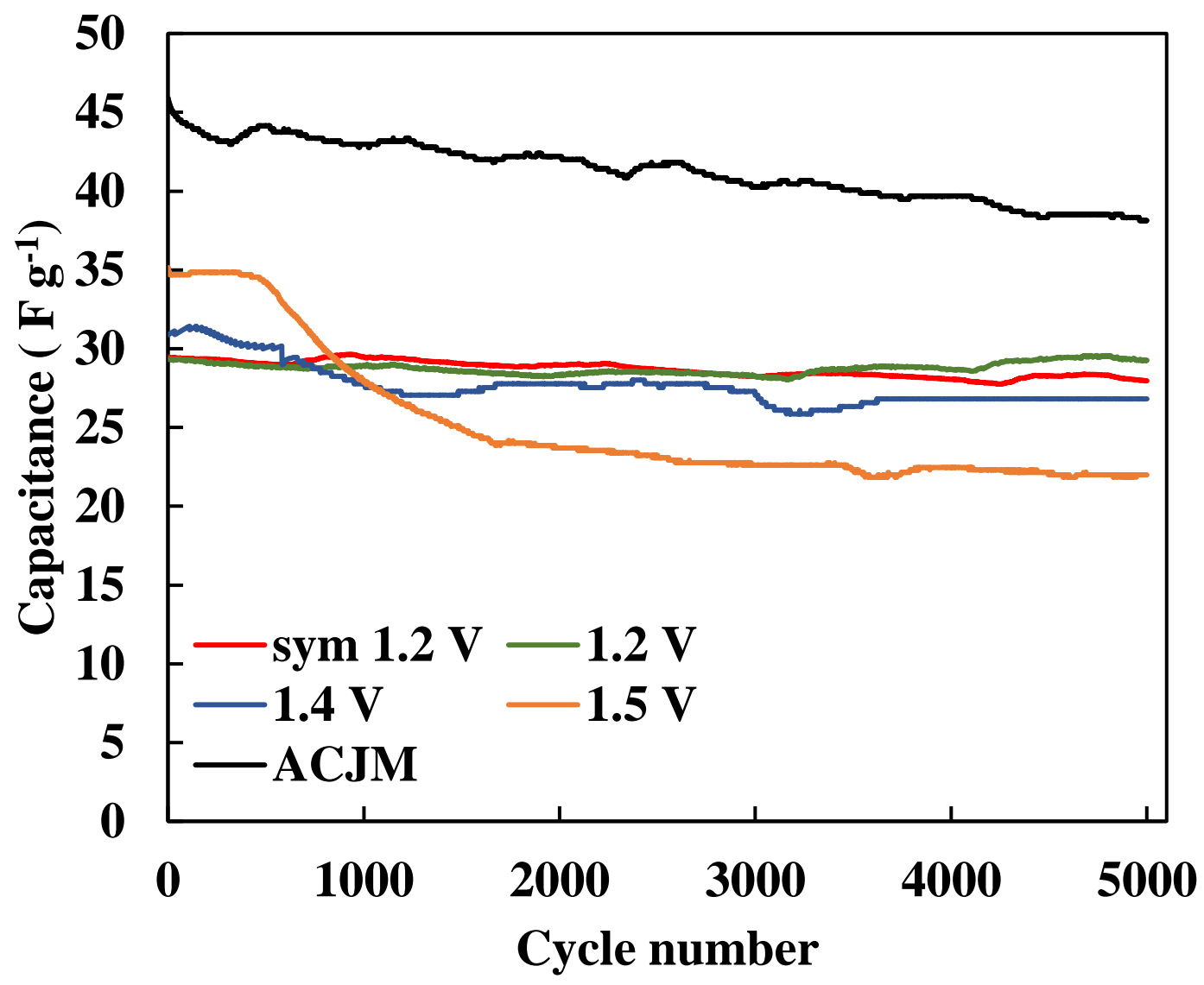

Figure 8. GCD Durability tests of symmetric (cut-off voltage: $1.2 \mathrm{~V}$, red line) and asymmetric (1.2, 1.4 and $1.5 \mathrm{~V}$, green, blue and orange lines, respectively) L-B-900 capacitors. The symmetric ACJM capacitor (1.2 V, black line) is also included for comparison purposes. Specific current: $1 \mathrm{~A} \mathrm{~g} \mathrm{~g}^{-1}$. $1 \mathrm{M} \mathrm{H}_{2} \mathrm{SO}_{4}$ solution. 